\title{
Effects of dietary fructo-oligosaccharide supplementation on the growth performance, haemato-immunological parameters, gut microbiota and stress resistance of common carp (Cyprinus carpio) fry
}

\author{
Seyed Hossein Hoseinifar ${ }^{1 *}$, Narges Soleimani ${ }^{2}$ and Einar Ring $\varnothing^{3}$ \\ ${ }^{1}$ Department of Fisheries, Faculty of Fisheries and Environmental Sciences, Gorgan University of Agricultural Sciences \\ and Natural Resources, Gorgan, Iran \\ ${ }^{2}$ Department of Aquatic Animal Health, Faculty of Veterinary Medicine, University of Tehran, Tehran, Iran \\ ${ }^{3}$ Norwegian College of Fishery Science, Faculty of Biosciences, Fisheries and Economics, UiT The Arctic University of Norway, \\ NO-9037 Breivika, Norway
}

(Submitted 22 October 2013 - Final revision received 23 April 2014-Accepted 18 June 2014 - First published online 3 September 2014)

\begin{abstract}
The present study was conducted to investigate the effects of dietary fructo-oligosaccharide (FOS) (0, 1, 2 and $3 \%)$ supplementation on the growth performance, haemato-immunological parameters, cultivable autochthonous (non-adherent) intestinal microbiota and stress resistance of common carp (Cyprinus carpio) fry (3.23 (SEM 0.14) g). These parameters were measured after feeding the carp fry with the experimental diets for 7 weeks. Dietary FOS supplementation had no significant effects on the growth performance and food intake of carp fry compared with the control treatment. It also had no significant effects on the following haematological parameters: erythrocyte count; leucocyte counts (WBC); haematocrit; $\mathrm{Hb}$; mean corpuscular volume; mean corpuscular Hb content; mean corpuscular Hb concentration. However, WBC and respiratory burst activity were significantly affected by dietary FOS supplementation. Evaluation of the cultivable autochthonous intestinal microbiota revealed a significant increase in the levels of total viable heterotrophic aerobic bacteria and lactic acid bacteria in fish fed diets supplemented with 2 and 3\% FOS. Furthermore, dietary FOS supplementation significantly increased the survival rate and stress resistance of carp fry compared with the control treatment. These results encourage conducting further research on the administration of FOS and other prebiotics in carp fry studies.
\end{abstract}

Key words: Cyprinus carpio: Fructo-oligosaccharide: Growth performance: Haemato-immunological parameters: Gut microbiota: Stress resistance

Prebiotics are non-digestible food ingredients that beneficially affect the host by selectively stimulating the growth and/or activity of health-promoting bacteria in the intestinal tract ${ }^{(1)}$. Fructo-oligosaccharide (FOS or oligofructose) is a fructan with a degree of polymerisation (2-20) that is obtained by enzymatic hydrolysis of inulin ${ }^{(2)}$. FOS is present in a number of common foods such as garlic, onion, artichoke and asparagus ${ }^{(3)}$, and dietary FOS has received great attention as a prebiotic for aquatic animals ${ }^{(4,5)}$. Despite some contradictory results ${ }^{(5-7)}$, beneficial effects of dietary FOS supplementation on growth performance and survival ${ }^{(8-14)}$, gut microbiota ${ }^{(14,15)}$, immune response ${ }^{(12,16,17)}$ and digestive enzyme activity ${ }^{(12,13)}$ have been reported in several fish species.

Common carp (Cyprinus carpio) is a widespread freshwater fish and is the main aquaculture species in many European and Asian countries ${ }^{(18)}$. Considering the progress in culture methodologies, specifically elevation of the production by intensification of culture, which causes deterioration of water quality, stress to cultured organisms and outbreaks of infectious diseases, elevation of fish resistance and improvement of fish health status through dietary supplements are of importance in commercial carp aquaculture, especially in sensitive periods (i.e. larval and fry culture) ${ }^{(19)}$. However, despite the well-documented beneficial effects of prebiotics in finfish ${ }^{(4,5)}$, to our knowledge, there is no available information on the effects of dietary FOS supplementation in carp fry.

Therefore, the aim of the present study was to investigate the effects of dietary FOS supplementation on the growth performance, haemato-immunological parameters, culturable gut microbiota and stress resistance of common carp fry.

Abbreviations: FOS, fructo-oligosaccharide; Ht, haematocrit; LAB, lactic acid bacteria; WBC, leucocyte counts.

* Corresponding author: S. H. Hoseinifar, fax +98 2632227765, email hoseinifar@gau.ac.ir 


\section{Experimental methods}

\section{Prebiotic}

FOS used in the present study was kindly provided by Orafti (Raffinerie Tirlemontoise). According to the manufacturer, the chemical composition of the product was $98.2 \% \mathrm{DM}$ and $1 \cdot 8 \%$ crude ash.

\section{Experimental diets}

Experimental diets were prepared by supplementing a basal formulated diet with different levels ( $0 \%$ (control), 1\%, 2\% and $3 \%$ ) of FOS (Table 1). The ingredients were blended thoroughly in a mixer and pelleted using a meat grinder equipped with a $2 \mathrm{~mm}$ die. The pelleted diets were air-dried and stored in plastic bags at $4^{\circ} \mathrm{C}$ until further use.

\section{Fish culture and feeding trial}

A total of 480 common carp fry $(3 \cdot 23$ (SEM 0.14) g) obtained from the Siowal Caspian sea teleost fish propagation and cultivation centre (Golestan province, Iran) were acclimatised to the experimental conditions for 1 week. Thereafter, fish were randomly allocated to twelve 500-litre tanks (forty fish per tank and triplicate tanks per treatment). Water temperature, dissolved oxygen content and $\mathrm{pH}$ were monitored daily and maintained at $25 \cdot 74 \pm 1 \cdot 79^{\circ} \mathrm{C}, 7 \cdot 13(\operatorname{sem} 0.23) \mathrm{mg} / \mathrm{l}$ and $7 \cdot 11$ (SEM $0 \cdot 18$ ), respectively. Each tank was aerated continuously through an airstone connected to a central air compressor.

Table 1. Formulation (\%) and proximate composition of the experimental diets

\begin{tabular}{|c|c|c|c|c|}
\hline & Control & $1 \%$ & $2 \%$ & $3 \%$ \\
\hline \multicolumn{5}{|l|}{ Ingredients } \\
\hline Fishmeal & $40 \cdot 0$ & 39.8 & $39 \cdot 7$ & $39 \cdot 6$ \\
\hline Wheat flour & $21 \cdot 0$ & $20 \cdot 8$ & 20.5 & $20 \cdot 2$ \\
\hline Soyabean meal & 13.5 & 13.4 & $13 \cdot 2$ & $13 \cdot 1$ \\
\hline Gluten & 5.5 & 5.4 & $5 \cdot 2$ & $5 \cdot 1$ \\
\hline Soyabean oil & $6 \cdot 0$ & 5.9 & $5 \cdot 8$ & $5 \cdot 6$ \\
\hline Fish oil & $6 \cdot 0$ & 5.9 & $5 \cdot 8$ & $5 \cdot 6$ \\
\hline Mineral premix* & $3 \cdot 0$ & $3 \cdot 0$ & $3 \cdot 0$ & $3 \cdot 0$ \\
\hline Vitamin premix ${ }^{*}$ & $2 \cdot 0$ & $2 \cdot 0$ & $2 \cdot 0$ & $2 \cdot 0$ \\
\hline Bindert & $2 \cdot 0$ & $2 \cdot 0$ & $2 \cdot 0$ & $2 \cdot 0$ \\
\hline Antifungal agentł & 0.5 & 0.5 & 0.5 & 0.5 \\
\hline Antioxidant§ & 0.5 & 0.5 & 0.5 & 0.5 \\
\hline FOS\| & 0.0 & 1.0 & $2 \cdot 0$ & $3 \cdot 0$ \\
\hline \multicolumn{5}{|c|}{ Proximate analysis (\% DM basis) } \\
\hline DM & $89 \cdot 50$ & 89.41 & 89.64 & $89 \cdot 60$ \\
\hline Crude protein & $38 \cdot 22$ & $38 \cdot 30$ & $38 \cdot 21$ & 38.29 \\
\hline Crude lipid & $10 \cdot 24$ & $10 \cdot 20$ & $10 \cdot 28$ & $10 \cdot 21$ \\
\hline Ash & 3.45 & 3.50 & 3.40 & 3.60 \\
\hline Fibre & $11 \cdot 20$ & $11 \cdot 30$ & $11 \cdot 20$ & 11.40 \\
\hline NFEף & $26 \cdot 39$ & $26 \cdot 11$ & $26 \cdot 55$ & $26 \cdot 10$ \\
\hline Energy $(\mathrm{MJ} / \mathrm{kg})^{\star \star}$ & 17.55 & $17 \cdot 50$ & 17.59 & $17 \cdot 50$ \\
\hline
\end{tabular}

FOS, fructo-oligosaccharide; NFE, nitrogen-free extracts.

* Premix detailed by Hoseinifar et al. ${ }^{(15)}$.

†Amet binder ${ }^{\mathrm{TM}}$; Mehr Taban-e-Yazd.

‡ToxiBan antifungal agent (Vet-A-Mix; Shenandoah).

$\S$ Butylated hydroxytoluene (Merck).

IIFOS; Raffinerie Tirlemontoise (FOS content $>93 \%$ ).

1 NFE = DM - (crude protein + crude lipid + ash + fibre)

** Gross energy (MJ/kg) calculated according to $23.6 \mathrm{~kJ} / \mathrm{g}$ for protein, $39.5 \mathrm{~kJ} / \mathrm{g}$ for lipid and $17.0 \mathrm{~kJ} / \mathrm{g}$ for NFE.
During the rearing experiment ( 7 weeks), fish were handfed to apparent satiation twice a day (09.00 and 15.00 hours). Uneaten feed was collected $1 \mathrm{~h}$ after feeding and dried at $60^{\circ} \mathrm{C}^{(20)}$.

\section{Determination of growth performance and survival rate}

The growth performance parameters including weight gain (\%), specific growth rates (SGR), condition factor (CF), feed conversion ratio (FCR) and survival rate were calculated according to the following formulae:

$$
\begin{gathered}
\text { Weight gain }(\%)=W_{2}-W_{1}, \\
\text { SGR }=100\left(\ln W_{2}-\ln W_{1}\right) / T, \\
\mathrm{CF}=100 \times(\text { body weight }(\mathrm{g})) /(\operatorname{body} \text { length }(\mathrm{cm}))^{3}, \\
\mathrm{FCR}=\mathrm{FO} / \mathrm{WG},
\end{gathered}
$$

where $W_{1}$ is the initial weight $(\mathrm{g}), W_{2}$ is the final weight $(\mathrm{g})$, $T$ is time (d), FO is the feed provided ( $g$ ) and WG is the weight gain $(\mathrm{g})$,

$$
\text { Survival rate }=\left(N_{\mathrm{f}} / N_{0}\right) \times 100,
$$

where $N_{0}$ is the initial number of fish and $N_{\mathrm{f}}$ is the final number of fish.

\section{Haemato-immunological analysis}

At the end of the feeding trial, after 7 weeks, blood was collected from the caudal vein of carp fry (three fish per tank) for haemato-immunological analysis. Whole blood was suspended in the Natt \& Herrick diluent ${ }^{(21)}$ for performing erythrocyte counts and total leucocyte counts (WBC) using a haemocytometer. Haematocrit $(\mathrm{Ht})$ was determined using the micro-Ht method as described by Brown ${ }^{(22)}$, and $\mathrm{Ht}$ values are reported as packed cell volume percentage. $\mathrm{Hb}$ levels were estimated using Sahli's method ${ }^{(23)}$. Differential WBC (neutrophils, lymphocytes and monocytes) were performed using May-Grunwald-Giemsa-stained blood smears.

The respiratory burst activity was measured in triplicate by chemiluminescent assay (measurement of light emission) based on the modified protocol of Mathews et al. ${ }^{(24)}$ as described by Khoshbavar-Rostami et al. ${ }^{(25)}$ using an automated system for chemiluminescent analysis (Luminoskan Ascent T392; Thermo Fisher Scientific, Inc.).

\section{Quantification of autochthonous intestinal microbiota}

Samples of the entire intestine of fifteen fish were used for quantifying total viable autochthonous heterotrophic aerobic bacteria and lactic acid bacteria (LAB) at the start and end of the experiment as described previously ${ }^{(15)}$. Samples were processed on an individual basis and were not pooled. Dilutions $(100 \mu \mathrm{l})$ were spread in triplicate onto Plate Count Agar medium (Merck) and de Man, Rogosa and Sharpe medium (Merck) for quantifying total viable heterotrophic aerobic bacteria and LAB, respectively. The plates were incubated at room temperature $\left(25^{\circ} \mathrm{C}\right)$ for $5 \mathrm{~d}$ and colony-forming units (CFU)/g 
Table 2. Growth performance parameters and survival rate of common carp fry fed diets supplemented with varying levels of fructo-oligosaccharide for 7 weeks

(Mean values with their standard errors)

\begin{tabular}{|c|c|c|c|c|c|c|c|c|}
\hline & \multicolumn{2}{|c|}{ Control } & \multicolumn{2}{|c|}{$1 \%$} & \multicolumn{2}{|c|}{$2 \%$} & \multicolumn{2}{|c|}{$3 \%$} \\
\hline & Mean & SEM & Mean & SEM & Mean & SEM & Mean & SEM \\
\hline Initial weight (g) & 3.35 & 0.15 & $3 \cdot 30$ & 0.11 & $3 \cdot 20$ & 0.20 & $3 \cdot 10$ & $0 \cdot 18$ \\
\hline Final weight $(\mathrm{g})^{*}$ & 9.79 & 0.29 & 9.35 & 0.62 & 9.57 & 0.25 & $10 \cdot 10$ & 0.41 \\
\hline Weight gain (\%)† & $192 \cdot 20$ & 6.03 & 178.68 & 14.46 & 199.61 & 13.65 & $225 \cdot 22$ & 18.57 \\
\hline SGR & 1.91 & 0.11 & 1.85 & 0.16 & 1.95 & 0.12 & 2.05 & 0.15 \\
\hline CF & 1.29 & 0.08 & $1 \cdot 30$ & 0.04 & $1 \cdot 30$ & 0.07 & 1.35 & 0.09 \\
\hline FCR $\ddagger$ & 3.48 & 0.11 & 3.71 & 0.45 & 3.51 & 0.26 & $3 \cdot 21$ & 0.31 \\
\hline Survival (\%)§ & $61 \cdot 60^{\mathrm{a}}$ & 7.07 & $83 \cdot 30^{a, b}$ & 9.37 & $78 \cdot 40^{\mathrm{a}, \mathrm{b}}$ & 11.73 & $98 \cdot 30^{\mathrm{b}}$ & $2 \cdot 40$ \\
\hline
\end{tabular}

SGR, specific growth rates; CF, condition factor; FCR, feed conversion ratio.

${ }^{\mathrm{a}, \mathrm{b}}$ Mean values within a row with unlike superscript letters were significantly different $(P>0.05)$

* $\alpha=0.05 ; \beta=0.17$.

$\dagger \alpha=0.05 ; \beta=0.15$

$\ddagger \alpha=0.05 ; \beta=0.11$

$\S \alpha=0.05 ; \beta=0.16$.

were calculated from statistically viable plates (i.e. plates containing thirty to 300 colonies) ${ }^{(26)}$.

\section{Salinity stress challenge test}

Salinity stress challenge test was carried out at the end of the feeding trial according to the method of Hoseinifar et al. ${ }^{(20)}$. A total of fifteen fish were sampled from each tank and subjected to salinity stress challenge. The fry were exposed to $15 \mathrm{~g} / \mathrm{l}$ salinity in triplicate (fifteen fish per tank). The survival rates of fish were calculated $72 \mathrm{~h}$ after the challenge.

\section{Statistical analyses}

Statistical analyses were conducted using SPSS statistical package version 17.0 (SPSS, Inc.). Each tank served as the unit of analysis. All data were subjected to a one-way ANOVA to test the effects of dietary FOS supplementation on the haemato-immunological parameters, growth performance, culturable gut microbiota and stress resistance of carp fry (C. carpio). Duncan's multiple range test was carried out when the differences were significant ${ }^{(27)}$. $P$ values $<0.05$ were considered to be statistically significant. Data are presented as mean values with their standard errors.

\section{Results}

The growth performance parameters of carp fry fed experimental diets containing different levels of FOS are summarised in Table 2. There were no significant differences in the initial weight of the treatment groups $(P>0.05)$. Similarly, at the end of the feeding trial ( 7 weeks), no significant differences were observed in the final weights, WG, SGR, CF and FCR of common carp fry fed the FOS-supplemented diets and the control diet ( $P>0.05$; Table 2).

Calculation of survival rates at the end of the experiment revealed that dietary FOS supplementation significantly increased the survival rate of carp fry $(P<0.05$; Table 2$)$. Carp fry fed the $3 \%$ FOS diet exhibited the highest survival rate $(98.3$ (SEM 2.4)\%).

The effects of dietary FOS supplementation on the haematoimmunological parameters of carp fry are summarised in Tables 3 and 4. Statistical analyses revealed that erythrocyte count, mean corpuscular volume, mean corpuscular Hb content, mean corpuscular $\mathrm{Hb}$ concentration, $\mathrm{Hb}, \mathrm{Ht}$ and differential leucocyte counts were not significantly affected by dietary FOS supplementation ( $P>0.05$; Table 3$)$. WBC were significantly affected by $3 \%$ FOS supplementation $(P<0 \cdot 05$; Table 4$)$, while no effect of FOS supplementation was observed on lymphocyte, neutrophil and monocyte counts.

Table 3. Effects of dietary fructo-oligosaccharide (FOS) supplementation on the haematological parameters of common carp fry (Mean values with their standard errors)

\begin{tabular}{|c|c|c|c|c|c|c|c|c|c|c|c|c|}
\hline \multirow[b]{2}{*}{ Groups } & \multicolumn{2}{|c|}{$\begin{array}{c}\text { Erythrocyte } \\
\text { count }\left(\times 10^{6}\right. \\
\text { per } \mu \mathrm{l})^{\star}\end{array}$} & \multicolumn{2}{|c|}{$\mathrm{Hb}(\mathrm{mmol} / \mathrm{l}) \dagger$} & \multicolumn{2}{|c|}{$\begin{array}{l}\text { Haematocrit } \\
(\%) \ddagger\end{array}$} & \multicolumn{2}{|c|}{ MCV (fl) } & \multicolumn{2}{|c|}{$\mathrm{MCH}(\mathrm{pg})$} & \multicolumn{2}{|c|}{$\begin{array}{c}\mathrm{MCHC} \\
(\mathrm{mmol} / \mathrm{l})\end{array}$} \\
\hline & Mean & SEM & Mean & SEM & Mean & SEM & Mean & SEM & Mean & SEM & Mean & SEM \\
\hline Control & 1.49 & 0.26 & 3.41 & 0.25 & 23.00 & 3.60 & 155.07 & $19 \cdot 60$ & $34 \cdot 16$ & 4.39 & 13.69 & 0.92 \\
\hline $1 \%$ FOS & 1.62 & 0.20 & 3.08 & 0.31 & $23 \cdot 66$ & 3.51 & 145.63 & 13.90 & 30.54 & 6.09 & $13 \cdot 02$ & 2.44 \\
\hline $2 \%$ FOS & 1.55 & $0 \cdot 11$ & $3 \cdot 28$ & 0.25 & $23 \cdot 60$ & $3 \cdot 78$ & $152 \cdot 30$ & $19 \cdot 87$ & $34 \cdot 15$ & $4 \cdot 20$ & 14.08 & 1.98 \\
\hline $3 \%$ FOS & 1.65 & 0.17 & 3.22 & 0.12 & $25 \cdot 00$ & $2 \cdot 64$ & $151 \cdot 29$ & 13.66 & 31.88 & $4 \cdot 19$ & 13.08 & 1.57 \\
\hline
\end{tabular}

$\mathrm{MCV}$, mean corpuscular volume; $\mathrm{MCH}$, mean corpuscular $\mathrm{Hb}$ content; $\mathrm{MCHC}$, mean corpuscular $\mathrm{Hb}$ concentration.

${ }^{\star} \alpha=0.05 ; \beta=0.10$.

† $\alpha=0.05 ; \beta=0.14$

$\ddagger \alpha=0.05 ; \beta=0.13$. 
Table 4. Differential leucocyte counts of common carp fry fed diets supplemented with different levels of fructo-oligosaccharide (FOS) for 7 weeks

(Mean values with their standard errors)

\begin{tabular}{|c|c|c|c|c|c|c|c|c|}
\hline \multirow[b]{2}{*}{ Groups } & \multicolumn{2}{|c|}{$\begin{array}{l}\text { Leucocyte count } \\
\left(\times 10^{3} \text { per } \mu \mathrm{l}\right)^{\star}\end{array}$} & \multicolumn{2}{|c|}{$\begin{array}{l}\text { Lymphocytes } \\
(\%)\end{array}$} & \multicolumn{2}{|c|}{$\begin{array}{c}\text { Neutrophils } \\
(\%)\end{array}$} & \multicolumn{2}{|c|}{$\begin{array}{c}\text { Monocytes } \\
(\%)\end{array}$} \\
\hline & Mean & SEM & Mean & SEM & Mean & SEM & Mean & SEM \\
\hline Control & $32 \cdot 66^{a}$ & 2.08 & $92 \cdot 33^{a}$ & 2.08 & $5 \cdot 66^{a}$ & 0.57 & $2 \cdot 01^{a}$ & 0.32 \\
\hline $1 \%$ FOS & $36 \cdot 26^{a, b}$ & 3.55 & $93.03^{\mathrm{a}}$ & 1.25 & $5 \cdot 36^{\mathrm{a}}$ & 1.52 & $1 \cdot 61^{\mathrm{a}}$ & 0.70 \\
\hline $2 \%$ FOS & $37 \cdot 33^{a, b}$ & $2 \cdot 81$ & $92.96^{\mathrm{a}}$ & 1.15 & $5 \cdot 33^{\mathrm{a}}$ & 1.15 & $1.71^{\mathrm{a}}$ & 0.41 \\
\hline $3 \%$ FOS & $39 \cdot 30^{\mathrm{b}}$ & $1 \cdot 15$ & $92 \cdot 60^{\mathrm{a}}$ & 2.64 & $5 \cdot 60^{a}$ & 1.63 & $1 \cdot 80^{\mathrm{a}}$ & 0.90 \\
\hline
\end{tabular}

a,b Mean values within a column with unlike superscript letters were significantly different $(P>0.05)$.

${ }^{*} \alpha=0.05 ; \beta=0.12$.

Dietary FOS supplementation significantly increased the respiratory burst activity compared with the control treatment $(P<0 \cdot 05$; Fig. 1).

The levels of total heterotrophic autochthonous gut bacteria in the control group (4.05 (SEM 0.07) CFU/g) were significantly lower than those in carp fry fed the FOS-supplemented diets $(P<0.05$; Fig. 2). Total autochthonous intestinal heterotrophic bacteria levels were significantly higher in the 2 and $3 \%$ FOS groups (5.68 (SEM 0.10) and 5.57 (SEM 0.24) CFU/g, respectively). However, no cultivable LAB were detected in the control and 1\% FOS groups; the 2 and 3\% FOS groups had 1.50 (SEM 0.04) and 2.42 (SEM 0.06) CFU/g of autochthonous LAB, respectively (Fig. 2).

The results of the salinity challenge test are shown in Fig. 3. Low survival rates were observed $72 \mathrm{~h}$ after the challenge in the control group, while carp fry fed the FOS-supplemented diets had significantly improved the survival rate $(P<0.05$; Fig. 3). The survival rates of the 1,2 and $3 \%$ FOS groups were 53.4 (SEM 3.9), 57.7 (SEM 4.52) and 59.6 (SEM 8.16)\%, respectively.

\section{Discussion}

To our knowledge, this is the first study to investigate the effects of dietary FOS supplementation on the growth performance, haemato-immunological parameters, cultivable gut microbiota and stress resistance of common carp fry. The results of the present study showed that 1, 2 or $3 \%$ FOS supplementation had no significant effects on the growth performance of carp fry. These results are not in accordance with those of previous studies in blunt snout bream (Megalobrama amblycephala) fingerlings ${ }^{(13)}$, stellate sturgeon (Acipenser stellatus) juveniles ${ }^{(14)}$, farmed rainbow trout (Oncorbynchus mykiss) ${ }^{(28)}$ and red drum (Sciaenops ocellatus) ${ }^{(17)}$. However, Hoseinifar et al. ${ }^{(15)}$ and GrisdaleHelland et $a l .{ }^{(29)}$ reported that dietary FOS supplementation had no significant effects on the growth performance of beluga (Huso buso) juveniles and Atlantic salmon (Salmo salar). The differences observed in the results of these studies might be due to the different methods of prebiotic administration, dosage levels, different intestinal morphology, gut microbiota and life stages ${ }^{(11)}$.

Dietary FOS supplementation significantly increased the survival rate of common carp fry compared with the control treatment. Similarly, improved survival of cobia (Rachycentron canadum) larvae ${ }^{(30)}$, rainbow trout ${ }^{(31)}$ and beluga juveniles ${ }^{(15)}$ has been observed upon prebiotic administration. Akrami et al. ${ }^{(14)}$ reported that the survival rate of stellate sturgeon juveniles was not affected by 1 or $2 \%$ dietary FOS supplementation. The improved survival rate of prebiotic-fed cultured organisms might be due to improved general health or immune status, as reported previously $^{(12)}$, but further investigations are needed to clarify the underlying mechanisms.

Haemato-immunological parameters are valuable tools for the determination of cultured organism health status ${ }^{(32)}$. These parameters have been widely used in prebiotic studies for the evaluation of changes in health status as a result of prebiotic administration ${ }^{(4,6)}$. The results of the present study showed that dietary FOS supplementation had no significant effects on haematological parameters including erythrocyte count, mean corpuscular volume, mean corpuscular $\mathrm{Hb}$ content, mean corpuscular $\mathrm{Hb}$ concentration, $\mathrm{Hb}$, $\mathrm{Ht}$ and differential leucocyte counts, but the significantly higher WBC values in the prebiotic-fed fish are in accordance with the results of the study carried out by Akrami et $a l .{ }^{(14)}$. Similar elevation of WBC has been observed in beluga $\left(H\right.$. huso) juveniles fed $\operatorname{FOS}^{(16)}$. In the present study, dietary FOS supplementation increased the respiratory burst activity compared with the control treatment.

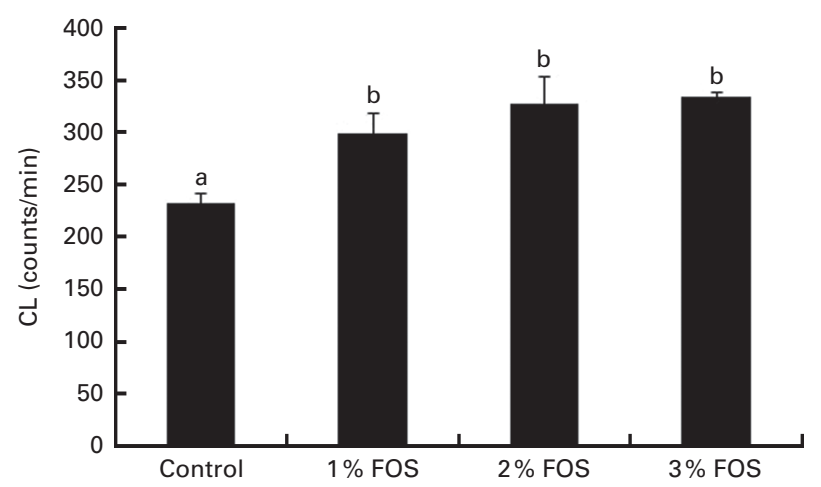

Fig. 1. Respiratory burst activity (chemiluminescence $(\mathrm{CL})$ response; light emission count $/ \mathrm{min})(\alpha=0.05 ; \beta=0.17)$ of carp fry fed diets supplemented with different levels ( $0 \%$ (control), $1 \%, 2 \%$ and $3 \%$ ) of fructo-oligosaccharide (FOS) for 7 weeks. Values are means, with their standard errors represented by vertical bars. ${ }^{a, b}$ Mean values with unlike letters were significantly different $(P<0.05)$. 

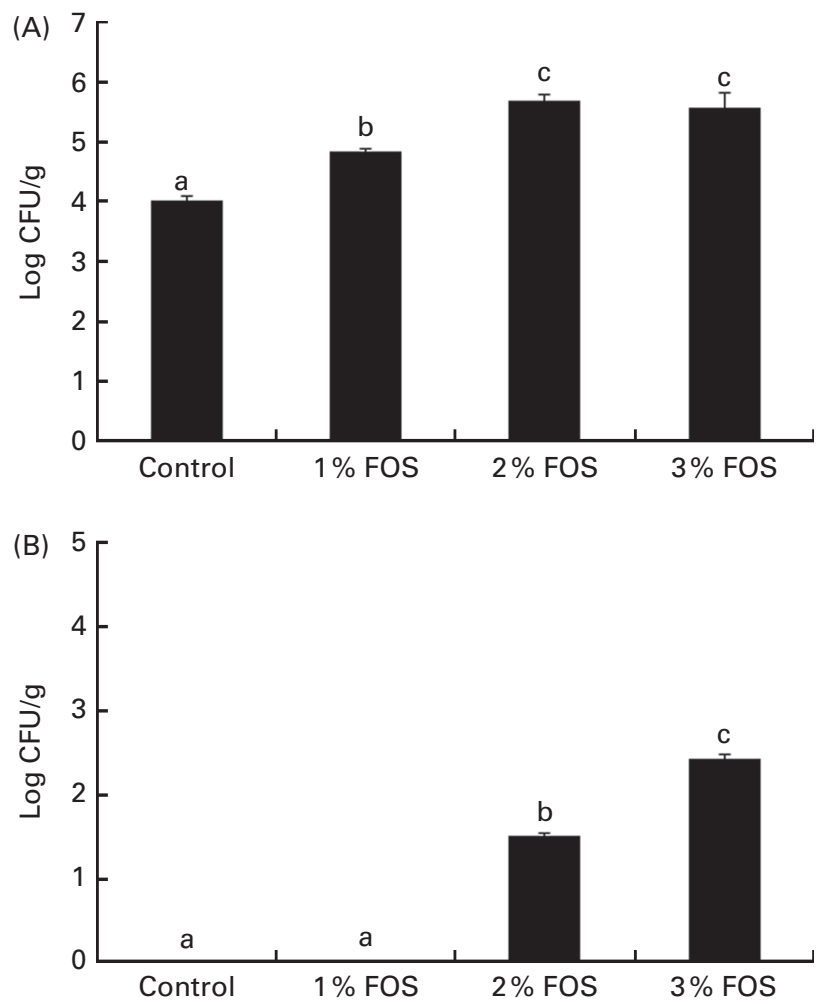

Fig. 2. Levels of total culturable autochthonous bacteria (A) $(\alpha=0.05$; $\beta=0.14)$ and autochthonous lactic acid bacteria (B) $(\alpha=0.05 ; \beta=0.12)$ (log colony-forming units (CFU)/g intestine) of carp fry fed diets supplemented with different levels ( $0 \%$ (control), $1 \%, 2 \%$ and $3 \%$ ) of fructooligosaccharide (FOS) for 7 weeks. Values are means, with their standard errors represented by vertical bars. ${ }^{a, b, c}$ Mean values with unlike letters were significantly different $(P<0.05)$.

Similarly, previous studies on the effects of synbiotic administration in large yellow croaker (Larimichthys crocea $)^{(33)}$, gilthead sea bream (Sparus aurata L.) ${ }^{(34)}$ and koi $\left(C\right.$. carpio koi ${ }^{(35)}$ revealed a significantly higher respiratory burst activity. In contrast to these results, Akrami et $a l^{(14)}$ reported that FOS supplementation had no effect on the respiratory burst activity of stellate sturgeon. Respiratory bursts, produced by phagocytes to attack invasive pathogens during phagocytosis, have been widely used for the evaluation of defence ability against pathogens ${ }^{(36)}$. Elevation of WBC and respiratory burst activity observed in the present study is probably caused by the stimulation of carp immune response due to FOS supplementation.

The intestinal microbiota of fish is a complex and dynamic ecosystem containing a diverse community of micro-organism $^{(37,38)}$, and genetic, nutritional and environmental factors are the main factors that modulate the intestinal microbiota ${ }^{(39)}$. Although LAB are considered a minor constitute of the intestinal microbiota of several fish species, they have been considered to be beneficial components of the fish intestine ${ }^{(40)}$. Modulation of the intestinal microbiota of fish towards beneficial communities (i.e. LAB) has been studied through the administration of probiotics, prebiotics and synbiotics ${ }^{(4,41)}$. The levels of cultivable autochthonous intestinal microbiota observed in the present study revealed that dietary FOS supplementation significantly increased the levels of total autochthonous intestinal heterotrophic bacteria. In addition, the levels of LAB were significantly elevated in common carp fed the 2 and $3 \%$ FOS diets. However, further studies using more sensitive molecular methods such as denaturing gradient gel electrophoresis (DGGE) and 16S rRNA sequencing are required to identify the LAB species to confirm their beneficial effects in common carp fry. Similar to the present results, FOS has been reported to increase the levels of total cultivable autochthonous intestinal heterotrophic bacteria and LAB in stellate sturgeon ${ }^{(14)}$ and beluga juveniles ${ }^{(15)}$. The results of the present study confirmed that modulation of the intestinal microbiota of carp can be achieved through dietary FOS supplementation, but further investigations are needed.

Resistance during exposure to abrupt changes in water salinity (salinity stress test) has been considered an important indicator of fry quality in nutrition trials, especially in prebiotic studies $^{(20,30,42,43)}$. The results of the present study revealed that dietary FOS supplementation significantly increased fish resistance in the salinity stress challenge test compared with the control treatment. Similarly, Soleimani et al. ${ }^{(12)}$ reported that Caspian roach (Rutilus rutilus) fry fed 3\% dietary FOS exhibited significantly higher resistance in salinity stress challenge test, and this is in accordance with previous reports on Caspian roach fed galacto-oligosaccharide ${ }^{(20)}$ and cobia ${ }^{(30)}$ and white sea bream larvae (Diplodus sargus L.) ${ }^{(44)}$ fed mannan oligosaccharide. Although not confirmed in the present study, the main reason for the prebiotic effects on salinity stress resistance has been suggested to be the improved alignment of microvilli ${ }^{(44)}$, and evaluation of microvillus alignment will be included in further prebiotic studies.

In conclusion, dietary FOS supplementation had no significant effects on the growth performance and haematological parameters of carp fry, but significantly increased WBC and respiratory burst activity and modulated cultivable autochthonous gut microbiota levels and stress resistance. The positive results obtained encourage conducting further research on the

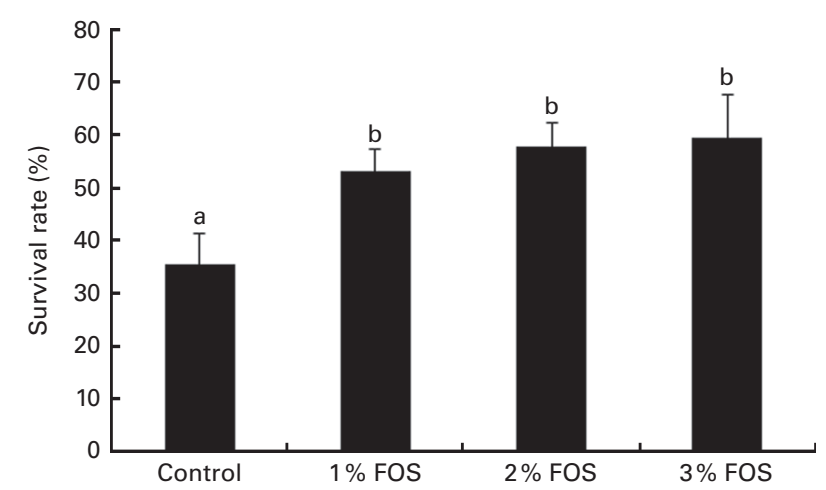

Fig. 3. Survival rate of carp fry fed diets supplemented with different levels ( $0 \%$ (control), $1 \%, 2 \%$ and $3 \%$ ) of fructo-oligosaccharide (FOS) for 7 weeks after exposure to salinity stress challenge (exposure to $15 \mathrm{~g} / \mathrm{l}$ water salinity for $72 \mathrm{~h})(\alpha=0.05 ; \beta=0.19)$. Values are means, with their standard errors represented by vertical bars. ${ }^{\mathrm{a}, \mathrm{b}}$ Mean values with unlike letters were significantly different $(P<0.05)$. 
administration of FOS and other prebiotics in common carp fry studies. Determination of the mechanisms of action and optimal inclusion levels is a topic that merits further research.

\section{Acknowledgements}

The authors are grateful to Orafti Company (Raffinerie Tirlemontoise) for its support and provision of FOS and to Professor Van Loo and Dr Mahious for their kind help and guidance. They also thank Dr Khoshbavar Rostami, Dr Yelghi, Mr Kor, Mr Fazel, Mr Binaii, and the staff at Gharesoo Research Station for their support during the study.

The present study was supported by grants from the Gorgan University of Agricultural Sciences and Natural Resources. The funder had no role in the design and analysis of the study or in the writing of this article.

The authors' contributions are as follows: S. H. H. contributed to the study design, conducted the study and analysed the samples, interpreted the data and wrote a draft of the manuscript; N. S. contributed to the conduction of the study; E. R. contributed to the interpretation of the results and improved the manuscript by critical comments.

None of the authors has any conflicts of interest to declare.

\section{References}

1. Gibson GR (2004) Fibre and effects on probiotics (the prebiotic concept). Clin Nutr Suppl 1, 25-31.

2. Mahious A, Van Loo J \& Ollevier F (2006) Impact of the prebiotics, inulin and oligofructose on microbial fermentation in the spiral valve of Siberian sturgeon (Acipenser baerii). In Aqua, 9-13 May 2006, Florence, Italy. Baton Rouge, LA: World Aquaculture Society.

3. Van Loo J, Cummings J, Delzenne N, et al. (1999) Functional food properties of non-digestible oligosaccharides: a consensus report from the ENDO project (DGXII AIRIICT94-1095). Br J Nutr 81, 121-132.

4. Ring $\varnothing$ E, Dimitroglou A, Hoseinifar SH, et al. (2014) Prebiotics in finfish: an update. In Aquaculture Nutrition: Gut Health, Probiotics and Prebiotics, 1st ed., pp. 416 [D 1 Merrifield and E Ringø, editors]. Hoboken, NJ: Wiley-Blackwell.

5. Ring $\varnothing$ E, Olsen RE, Gifstad TØ, et al. (2010) Prebiotics in aquaculture: a review. Aquacult Nutr 16, 117-136.

6. Merrifield DL, Dimitroglou A, Foey A, et al. (2010) The current status and future focus of probiotic and prebiotic applications for salmonids. Aquaculture 302, 1-18.

7. Anguiano M, Pohlenz C, Buentello A, et al. (2013) The effects of prebiotics on the digestive enzymes and gut histomorphology of red drum (Sciaenops ocellatus) and hybrid striped bass (Morone chrysops $\times$ M. saxatilis). Br J Nutr 109, 623-629.

8. Mahious AS \& Ollevier F (2005) Probiotics and prebiotics in aquaculture: a review. In 1st Regional Workshop on Techniques for Enrichment of Live Food for Use in Larviculture, 7-11 March 2005, Urima, Iran, pp. 17-26.

9. Mahious AS, Gatesoupe FJ, Hervi M, et al. (2006) Effect of dietary inulin and oligosaccharides as prebiotics for weaning turbot, Psetta maxima (Linnaeus, C. 1758). Aquacult Int 14, 219-229.

10. Zhou Q-C, Buentello JA \& Gatlin DM III (2010) Effects of dietary prebiotics on growth performance, immune response and intestinal morphology of red drum (Sciaenops ocellatus). Aquaculture 309, 253-257.

11. Hoseinifar SH, Zare P \& Merrifield DL (2010) The effects of inulin on growth factors and survival of the Indian white shrimp larvae and postlarvae (Fenneropenaeus indicus). Aquacult Res 41, e348-e352.

12. Soleimani N, Hoseinifar SH, Merrifield DL, et al. (2012) Dietary supplementation of fructooligosaccharide (FOS) improves the innate immune response, stress resistance, digestive enzyme activities and growth performance of Caspian roach (Rutilus rutilus) fry. Fish Shellfish Immunol 32, 316-321.

13. Wu Y, Liu WB, Li HY, et al. (2013) Effects of dietary supplementation of fructooligosaccharide on growth performance, body composition, intestinal enzymes activities and histology of blunt snout bream (Megalobrama amblycephala) fingerlings. Aquacult Nutr 19, 886-894.

14. Akrami R, Iri Y, Khoshbavar Rostami H, et al. (2013) Effect of dietary supplementation of fructooligosaccharide (FOS) on growth performance, survival, lactobacillus bacterial population and hemato-immunological parameters of stellate sturgeon (Acipenser stellatus) juvenile. Fish Shellfish Immunol 35, 1235-1239.

15. Hoseinifar SH, Mirvaghefi A, Mojazi Amiri B, et al. (2011) The effects of oligofructose on growth performance, survival and autochthonous intestinal microbiota of beluga (Huso buso) juveniles. Aquacult Nutr 17, 498-504.

16. Hoseinifar SH, Mirvaghefi A, Merrifield DL, et al. (2011) The study of some haematological and serum biochemical parameters of juvenile beluga (Huso huso) fed oligofructose. Fish Physiol Biochem 37, 91-96.

17. Buentello JA, Neill WH \& Gatlin DM III (2010) Effects of dietary prebiotics on the growth, feed efficiency and non specific immunity of juvenile red drum Sciaenops ocellatus fed soybean based diets. Aquacult Res 41, 411-418.

18. Naylor RL, Goldburg RJ, Primavera JH, et al. (2000) Effect of aquaculture on world fish supplies. Nature 405, 1017-1024.

19. Zhou Q, Li K, Jun X, et al. (2009) Role and functions of beneficial microorganisms in sustainable aquaculture. Bioresour Technol 100, 3780-3786.

20. Hoseinifar SH, Khalili M, Khoshbavar Rostami H, et al. (2013) Dietary galactooligosaccharide affects intestinal microbiota, stress resistance, and performance of Caspian roach (Rutilus rutilus) fry. Fish Shellfish Immunol 35, 1416-1420.

21. Natt MP \& Herrick CA (1952) A new blood diluent for counting the erythrocytes and leucocytes of the chicken. Poult Sci 31, 735-738.

22. Brown B (1988) Routine hematology procedures. In Hematology: Principles and Procedures, pp. 7-122. Philadelphia, PA: Leo and Fabiger.

23. Blaxhall PC \& Daisley KW (1973) Routine haematological methods for use with fish blood. J Fish Biol 5, 771-781.

24. Mathews ES, Warinner JE \& Weeks BA (1990) Assay of immune function in fish macrophages. In Techniques in Fish Immunology, vol. 2, pp. 155-163 [JS Stolen, TC Fletcher, DP Anderson, BS Roberson and WB van Muiswinkel, editors]. Fair Haven, NJ: SOS Publications.

25. Khoshbavar-Rostami H, Soltani M \& Hassan H (2006) Immune response of great sturgeon (Huso buso) subjected to long-term exposure to sublethal concentration of the organophosphate, diazinon. Aquaculture 256, 88-94.

26. Rawling MD, Merrifield DL \& Davies SJ (2009) Preliminary assessment of dietary supplementation of Sangrovit on red tilapia (Oreochromis niloticus) growth performance and health. Aquaculture 294, 118-122. 
27. Zar JH (1994) Biostatistical Analysis, 5th ed. Upper Saddle River, NJ: Prentice-Hall.

28. Ortiz L, Rebolé A, Velasco S, et al. (2013) Effects of inulin and fructooligosaccharides on growth performance, body chemical composition and intestinal microbiota of farmed rainbow trout (Oncorbynchus mykiss). Aquacult Nutr 19, 475-482.

29. Grisdale-Helland B, Helland SJ \& Gatlin DM III (2008) The effects of dietary supplementation with mannanoligosaccharide, fructooligosaccharide or galactooligosaccharide on the growth and feed utilization of Atlantic salmon (Salmo salar). Aquaculture 283, 163-167.

30. Salze G, McLean E, Schwarz MH, et al. (2008) Dietary mannan oligosaccharide enhances salinity tolerance and gut development of larval cobia. Aquaculture 274, $148-152$.

31. Staykov Y, Spring P, Denev S, et al. (2007) Effect of a mannan oligosaccharide on the growth performance and immune status of rainbow trout (Oncorbynchus mykiss). Aquacult Int 15, 153-161.

32. Cnaani A, Tinman S, Avidar Y, et al. (2004) Comparative study of biochemical parameters in response to stress in Oreochromis aureus, O. mossambicus and two strains of O. niloticus. Aquacult Res 35, 1434-1440.

33. Ai Q, Xu H, Mai K, et al. (2011) Effects of dietary supplementation of Bacillus subtilis and fructooligosaccharide on growth performance, survival, non-specific immune response and disease resistance of juvenile large yellow croaker, Larimichthys crocea. Aquaculture 317, 155-161.

34. Cerezuela R, Cuesta A, Meseguer J, et al. (2012) Effects of dietary inulin and heat-inactivated Bacillus subtilis on gilthead seabream (Sparus aurata L.) innate immune parameters. Benef Microbes 3, 77-81.
35. Lin S, Mao S, Guan Y, et al. (2012) Effects of dietary chitosan oligosaccharides and Bacillus coagulans on the growth, innate immunity and resistance of koi (Cyprinus carpio koi). Aquaculture 342, 36-41.

36. Chiu C-H, Guu Y-K, Liu C-H, et al. (2007) Immune responses and gene expression in white shrimp, Litopenaeus vannamei, induced by Lactobacillus plantarum. Fish Shellfish Immunol 23, 364-377.

37. Ringø E \& Birkbeck T (1999) Intestinal microflora of fish larvae and fry. Aquacult Res 30, 73.

38. Ringø E, Strøm E \& Tabachek J (1995) Intestinal microflora of salmonids: a review. Aquacult Res 26, 773-789.

39. Pérez T, Balcázar JL, Ruiz-Zarzuela I, et al. (2010) Hostmicrobiota interactions within the fish intestinal ecosystem. Mucosal Immunol 3, 355-360.

40. Ring $\varnothing$ E \& Gatesoupe F-J (1998) Lactic acid bacteria in fish: a review. Aquaculture 160, 177-203.

41. Dimitroglou A, Merrifield DL, Carnevali O, et al. (2011) Microbial manipulations to improve fish health and production - a Mediterranean perspective. Fish Shellfish Immunol 30, 1-16.

42. Smith ME, Kane AS \& Popper AN (2004) Noise-induced stress response and hearing loss in goldfish (Carassius auratus). J Exp Biol 207, 427-435.

43. Taoka Y, Maeda H, Jo JY, et al. (2006) Growth, stress tolerance and non-specific immune response of Japanese flounder Paralichthys olivaceus to probiotics in a closed recirculating system. Fish Sci 72, 310-321.

44. Dimitroglou A, Davies SJ, Sweetman J, et al. (2010) Dietary supplementation of mannan oligosaccharide on white sea bream (Diplodus sargus L.) larvae: effects on development, gut morphology and salinity tolerance. Aquacult Res 41, e245-e251. 